\title{
TECNOLOGIA E SUBJETIVAÇÃO: A QUESTÃO DA AGÊNCIA
}

\section{Rosana Medeiros de Oliveira Universidade de Brasília}

RESUMO: As críticas ao sujeito da interioridade e às filosofias da consciência, que reputam a um indivíduo unificado e coerente a fonte de ação, têm atribuído a uma outra grande agência unificada a origem de toda ação. A linguagem, os discursos, a sociedade, a cultura, a história substituem o lugar do sujeito como agência. No entanto, continuam sendo instâncias purificadas às quais atribui-se o privilégio da ação. Abandona-se o sujeito, mas há uma continuidade idealista na qual a agência só pode estar no campo dos humanos-entre-eles. É contra essa atribuição da agência apenas aos humanos-entre-eles que está estruturado este texto, defendendo os híbridos, os coletivos sócio-técnicos e as máquinas. Este trabalho irá explorar conceitos de Gilles Deleuze, Félix Guattari, Bruno Latour e Pierre Lévy, articulando-os para a abordagem de uma concepção de subjetivação que escape da agência reputada unicamente aos humanos-entre-eles.

PALAVRAS-CHAVE: sujeito, coletivos sócio-técnicos, híbridos, dobra, subjetivação.

\section{TECHNOLOGY AND SUBJECTIVITY: THE AGENCY PROBLEM}

ABSTRACT: The criticism to the subject of interiority and to the philosophies of consciousness, which consider a unified and coherent individual the source of action, has atributed to another great unified agency the origin of all action. The language, the discourses, the society, the culture, the history replace the role of the subject as agency. However, they keep being unaldutered instances credited with the privilege of the action. The subject is discarded, but there is still an idealistic continuity sustaining that the agency can only be placed in the field of the human-among-themselves. This study is developed exactly to be against this prerrogative of an agency restricted to humans-among-themselves, as well as to defend the hybrids, the social technical collectives and the machines. This work will explore concepts from Gilles Deleuze, Felix Guattaari, Bruno Latour and Pierre Levy, articulating them in order to deal with a concept of subjectivity which could avoid the agency credited only to humans-among-themselves.

KEY-WORDS: subject, social technical collectives, hybrids, subjectivity

O sujeito da interioridade e as filosofias da consciência, que reputam a um indivíduo unificado e coerente a fonte de toda ação, são criticados por diversos autores que têm atribuído a uma outra grande agência unificada a origem de toda ação. A linguagem, os discursos, a sociedade, a cultura, a história substituem o lugar do sujeito como agência. No entanto, continuam sendo instâncias purificadas às quais atribui-se o privilégio da ação. Abandona-se o sujeito, mas há uma continuidade idealista na qual a agência só pode estar no campo dos "humanos-entre-eles". De um lado, o humano com o privilégio da ação, e, do outro, as coisas, os objetos prático-inertes. É contra essa atribuição da agência apenas aos "humanosentre-eles" que pretendo argumentar, defendendo os híbridos, os coletivos sócio-técnicos e as máquinas entendidas como acoplamentos heterogêneos que produzem efeitos. É preciso abandonar a noção de agência restrita aos humanos e perceber as diversas máquinas subjetivantes.

Em geral, as análises baseadas no discurso evitam a referência a um lugar interior, exteriorizando a subjetividade. No entanto, esta exteriorização da subjetividade costuma ser constituída exclusivamente por seres humanos e suas relações, que são as entidades que têm o privilégio da explanação. As outras entidades, como os objetos tecnológicos, são excluídas. São tratadas como algo sobre o que se fala. Ou seja, ao primado do sujeito têm-se apresentado algumas outras instâncias substitutas, como as sociedades, as epistêmes, as estruturas mentais, a linguagem, a cultura, a intersubjetividade etc., mas que mantêm a dicotomia agência-objetos. As coisas e técnicas ficam de um lado, o humano, a linguagem, a cultura, os valores ficam de outro - eis nosso hábito de separar e instituir fronteiras entre âmbitos que podem ser ao mesmo tempo objeto da experiência e fonte instituinte. Dessa forma, o essencialismo naturalista que supunha sujeitos e objetos como naturais e apriorísticos é substituído por um essencialismo social no qual uma única instância unificada - a dos "humanos-entre-eles" - funciona como agência e conti- 
nua justificando a bifurcação sociedade-natureza, sujeito-objeto, humano-máquina (DOMENÈCH, M.; TIRADO, F. \& GÓMEZ, L, 2001, p. 26).

No entanto, estes termos são instâncias purificadas. A distinção bem marcada entre agência - comumente reputada ao humano, ao sujeito, à linguagem, à sociedade etc. - e objetos, ou técnicas, ou máquinas, faz parte do que o sociólogo Bruno Latour (1994) denominou "projeto da modernidade", no qual a ação é relacionada a uma potência apenas, a potência dos "humanos-entre-eles", transformando o resto do mundo em objetos intermediários ou forças mudas. O projeto da modernidade consistia na operação de separar o sujeito do conhecimento do objeto a ser conhecido, a teoria como espaço purificado do conhecimento e a prática como local da ação ${ }^{1}$.

Esta perspectiva é abalada quando nos deparamos com os dispositivos-materiais e coletivossociotécnicos que moldam nossas formas de pensar. São os agenciamentos intermediários, as redes, que dão sentido aos termos natureza, sociedade, objeto, sujeito. Pois não há razão pura, nem um sujeito transcendental estável, nem os humanos-entre-eles, como pura agência, visto que desde o nascimento somos constituídos por meio de línguas, de máquinas, de sistemas de representação que irão estruturar nossas experiências. Quem pensa não é o sujeito nu, monádico, face ao objeto, nem grupos intersubjetivos, nem estruturas, línguas, epistemes, nem tampouco inconscientes sociais que pensam em nós. O pensamento não é um atributo de uma entidade unificada e senhora de si mesma, nem um centro ordenador em torno do qual giram tecnologias intelectuais, mas um efeito de coletivos heterogêneos. Não existem distinções reais e bem demarcadas entre os seres humanos e as técnicas. Estas não constituem regiões do ser fundamentalmente separadas. Sociedade, religião, língua, filosofia, ciência, técnica, não são forças reais, mas abstrações, dimensões de análise (LÉVY, 1998, p.13).

Estas macro-identidades ideais não possuem meios de ação. As entidades emergem a partir da "relação", do movimento, ou seja, da existência contínua, e não de uma essência permanente. O que há de primordial não são essências, mas vínculo, passagem, relação. Comumente o humano, a linguagem, a sociedade são considerados ponto de partida; no entanto, pretendo ressaltar que toda entidade ao ser analisada revela-se como uma rede em potencial. Ou seja, totalidade aberta, que possui múltiplas entradas, composta por uma série de elementos heterogêneos conectados.

Em sua obra "Jamais fomos modernos", Bruno Latour pretende abandonar o mundo das representações modernas de objetos e sujeitos e chegar aos "quase-objetos" ou "quase-sujeitos", ou seja, aos híbridos. O humano, para ele, não deve ser pensado por contraste às coisas. Deve-se pensar a existência de quase-objetos e quase-sujeitos em vez de pensar em uma pura liberdade da existência humana e em objetos prático-inertes. Não existe natureza de um lado e sociedade de outro, as duas não constituem pólos distintos. Os artefatos participam nos coletivos pensantes: da caneta ao aeroporto, dos alfabetos à televisão, dos computadores aos sinais de trânsito. É preciso perceber as grandes máquinas híbridas constituídas de pedras e humanos, tinta e papel, palavras e estradas de ferro, redes telefônicas e computadores: "estes grandes monstros heteróclitos que são as empresas, as administrações, as usinas, as universidades, os laboratórios, as comunidades e coletivos de todos os tipos" (LÉVY, 1998, p.191).

No entanto, Latour adverte que os híbridos são considerados comumente como misturas de formas puras. Dos híbridos, é comum a procura do que é proveniente dos sujeitos (ou da sociedade) e o que é proveniente dos objetos. Contudo, não há uma Natureza transcendental, exata, verdadeira e povoada de entidades (uma coisa-em-si) que foi um dia descoberta pelos humanos. Nem há um Social, um espaço puro do humano, dos humanos-entre-eles, que não seja também constituído pelos objetos, pela linguagem e pelos afetos e perceptos nem sempre capturados na linguagem. O autor, então, propõe uma modificação do lugar do objeto e do sujeito, tirá-los de sua posição de "coisa-em-si" para levá-los ao coletivo (os coletivos sociotécnicos) sem contudo aproximá-los da Sociedade.

Pierre Lévy é outro teórico que sustenta posição semelhante. Propõe dar um fim à polarização humanos e máquinas, escapando das oposições fáceis que colocam de um lado os humanos, a carne, e de outro as máquinas, o metal, o silício. Lévy defende a idéia de um coletivo pensante de humanos-coisas. Esse coletivo humanos-coisas seria dinâmico, repleto de "singularidades atuantes" e "subjetividades mutantes" totalmente afastados do sujeito da epistemologia quanto das estruturas formais "linguagem", "sociedade" etc. Em seu livro "As tecnologias da inteligência" (1998), afirma:

A distinção feita entre um mundo objetivo inerte e sujeitos-substâncias que são os únicos portadores de atividade e de luz está abolida. É preciso pensar em efeitos de subjetividade nas redes de interface e em mundos emergindo provisoriamente de condições ecológicas locais. (p.161)

Em outra passagem relaciona seu posicionamento com uma tendência da filosofia francesa re- 
presentada pelos autores por ele citados:

(...) Como os rizomas de Deleuze e Guattari, as redes de Latour ou de Callon não respeitam as distinções estabelecidas entre coisas e pessoas, sujeitos pensantes e objetos pensados, inerte e vivo. Tudo o que for capaz de produzir uma diferença em uma rede será considerado como um ator, e todo ator definirá a si mesmo pela diferença que ele produz. Esta concepção do ator nos leva, em particular, a pensar de forma simétrica os humanos e os dispositivos técnicos. As máquinas são feitas por humanos, elas contribuem para formar e estruturar o funcionamento das sociedades e as aptidões das pessoas, elas muitas vezes efetuam um trabalho que poderia ser feito por pessoas como você ou eu. Os dispositivos técnicos são portanto realmente atores por completo em uma coletividade que já não podemos dizer puramente humana, mas cuja fronteira está em permanente redefinição. (LÉVY, 1998, p.137)

Neste trecho, Lévy chama atenção para uma concepção de ator diferente da concepção tradicionalmente trabalhada nas ciências humanas, ou seja, aquela que relaciona ao humano toda fonte de ação. Para Lévy, o ator é caracterizado pela heterogeneidade de sua composição, de humanos e não-humanos, podendo ser qualquer pessoa, instituição ou coisa que produza efeitos no mundo e sobre ele mesmo. A palavra ator ganha nova dimensão, indicando acoplamentos heterogêneos que produzem efeitos, que constituem agências.

Essa noção de ator assemelha-se a noção de máquina utilizada por Félix Guattari. As máquinas, para Guattari, não se referem a um espaço purificado das técnicas, mas a uma organização de fluxos, a uma engrenagem de produção regida por forças que circulam e afetam o mundo. São mecanismos produtores e reprodutores e devem ser concebidos como "atratores que recurvam o mundo ao seu redor" (GUATTARI, 2000). Constituem acoplamentos heterogêneos que agenciam. Máquina, na acepção indicada por Guattari, consiste em uma tentativa de abandonar o vocabulário que torna possível remeter ao sujeito como agência, para substituí-lo por uma linguagem completamente nova que enfatize os acoplamentos heterogêneos que produzem efeitos. A noção de máquina aqui é de extrema importância pois repudia a esfera da ontologia, não se caracteriza pelo o que é - como os sujeitos - mas pelo que faz, pelos efeitos que produz. A linguagem idealista de almas e sujeitos é substituída por uma materialista, ligada às práticas, aos acoplamentos heterogêneos.

Portanto, pensar em coletivos que produzem agenciamentos, mas que não remetem simplesmente aos "humanos-entre-eles", à sociedade ou à linguagem, implica abandonar a noção de sujeito como centro e possibilidade para a ação. Félix Guattari argumenta que a subjetividade é fruto de um agenciamento social múltiplo, e não há porque separar homem e máquina. A relação do humano com a matéria - com a natureza, com os objetos, com as máquinas - é uma relação não de formatação, mas de acoplamento, de composição. O campo de subjetivação é constitutivo tanto do sujeito-objeto quanto do meio. Ou seja, a subjetivação em Guattari é pensada como um processo de agrupamento, de composição, de agenciamentos heterogêneos de corpos, práticas, juízos, técnicas.

Nesse sentido, falar em subjetividade é uma forma de tentar escapar à idéia tradicional de sujeito da consciência. Descentrar a questão do sujeito para a subjetividade. O sujeito é comumente compreendido como uma forma de apreensão pré-reflexiva, como unificador dos estados de consciência. No entanto, como afirma Guattari, o sujeito não é evidente, "não basta pensar para ser como o proclamava Descartes (...) o sujeito advém no momento em que o pensamento se obstina em apreender a si mesmo e se põe a girar como um pião enlouquecido" (2002, p. 17). O sujeito, nesse sentido, é um recurvar-se que cria uma interioridade aberta. Um espaço reflexivo. Há diversas formas de existir que se instauram fora da consciência. A proposta de falar em processos de subjetivação consiste na tentativa de falar dos diversos componentes que não passam necessariamente pelos indivíduos - como os processos socioeconômicos, as máquinas comunicativas, os complexos urbanos - mas que podem, em seu cruzamento, instaurar uma dobra, uma interioridade que emerge como "território existencial", fundando uma intencionalidade.

Nesta concepção, o sujeito tradicional das filosofias da consciência é abandonado, mas outro emerge em seu lugar. O sujeito passa a ser pensado como um espaço de montagem contínua, como um processo de subjetivação. Torna-se um artefato em constante engendramento, mas que não deixa de ter materialidade e capacidade de agenciamento. O problema consiste em concebê-lo como instância purificada, a-histórica ou independente da linguagem e dos coletivos sociotécnicos.

O filósofo Gilles Deleuze desenvolve uma proposta interessante para contornar a questão da intencionalidade do sujeito. De acordo com ele, a subjetivação como processo constitui um "dentro" que é "a dobra do fora". O conceito de dobra, utilizado por Deleuze, possibilita escapar ao dualismo de uma 
exterioridade absoluta e de uma interioridade unificada, ao permitir "localizar as dobras e as curvaturas pelas quais passam as regiões do ser, uma na outra" (LÉVY, 2003). Além disso, "A dobra é o acontecimento, a bifurcação que faz ser. Cada dobra, açãodobra ou paixão-dobra, é o surgimento de uma singularidade, o começo de um mundo" (LÉVY, 2003). A dobra mostra um cenário diferente daquele que opunha interior/exterior. Abandona-se, assim, a imagem de um círculo onde a parte interna corresponde ao "eu" e a externa ao "mundo".

Pensar os processos de subjetivação como dobra implica despojar o sujeito de toda identidade essencialista e de toda interioridade absoluta. A subjetividade é uma dobra do exterior. A "interioridade" dobrada não é um "sistema psicológico", mas uma superfície descontínua, um dobramento da exterioridade. Este conceito também evita recair no problema já identificado de uma exterioridade unificada, que funciona como um grande agenciamento - a Sociedade, o Discurso ou a Linguagem, por exemplo.

O conceito de dobra utilizado por Deleuze também é útil para explicar a possibilidade, lançada por Foucault, de um si mesmo constituído por um núcleo de resistência frente a poderes e saberes estabelecidos. Subjetivação como dobra significa pensar em termos dos efeitos da composição de forças, práticas e relações que operam para transformar o ser humano em variadas formas de sujeito, em seres capazes de tomar a si próprios como os sujeitos de suas próprias práticas, sem abandonar a dimensão dos coletivos sociotécnicos - implicados nos fluxos que se dobram - e de sua historicidade, atualizada nas práticas e instituições.

Nesse sentido, a noção de dobra permite ainda um reconhecimento das possibilidades de transformação e de criação que estão abertas. O sujeito não é apenas o espaço de cruzamento de forças - como na genealogia foucaultiana -, mas constitui-se ao mesmo tempo como uma força dobrada sobre si mesma. Tem agência, produz efeitos. Dessa forma, o sujeito passa a ter um caráter aberto, múltiplo, cambiante, inacabado e ao mesmo tempo pode escapar, criar linhas de fuga aos poderes e saberes que o subjetivam. O sujeito não foi aniquilado, nem desaparece, mas deve ser entendido como uma multiplicidade virtual, uma obra-em-andamento.

As noções de processo de subjetivação e dobra permitem que se pense em termos de hibridações, de coletivos de humanos e não-humanos. O espaço monádico da interioridade psicológica é abolido em favor da abertura da dobra. A agência não está mais restrita aos humanos-entre-eles, à Linguagem ou à Sociedade. Os agenciamentos são processos de com- posição que envolvem coletivos sociotécnicos.

Essa reflexão é essencial para uma análise que não polarize as tecnologias e os sujeitos. É preciso pensar em termos de coletivos sociotécnicos, e como estes estão imbricados nos processos de subjetivação, de singularização.

\section{NOTAS}

${ }^{1}$ É necessário ressaltar que Bruno Latour sustenta, no entanto, que jamais fomos modernos, pois, na prática, o sistema moderno de representação do mundo nunca funcionou de acordo com as separações que instituiu. As distinções radicais entre ciência e técnica, natureza e cultura, funcionam apenas como campos de abstrações, mas na prática os híbridos não deixaram de ser criados.

\section{REFERÊNCIAS}

DOMENÈCH, M.; TIRADO, F. \& GÓMEZ, L. A dobra: psicologia e subjetivação. Em: SILVA, Tomás Tadeu. Nunca fomos humanos: nos rastros do sujeito. Belo Horizonte: Autêntica. 2001.

GUATTARI, Félix. Caosmose: um novo paradigma estético. Trad. Ana L. de Oliveira \& Lícia C. Leão. São Paulo: Editora 34. 1992/2000.

GUATTARI , Félix. As três ecologias. Trad. Maria C. F. Bittencourt. Campinas, SP: Papirus, 13 edição. 1989/ 2002.

LATOUR, Bruno. Jamais fomos modernos: ensaio de antropologia simétrica. Trad.: Carlos Irineu da Costa. Rio de Janeiro: Ed. 34. 1991/1994.

LÉVY, Pierre. Plissê fractal ou como as máquinas de guattari podem nos ajudar a pensar o transcendental hoje. Internet, disponível em: http:// empresa.portoweb.com.br/pierreLévy/ plissefractal.html. Acesso em: 5 agosto 2003.

LÉVY, Pierre. As tecnologias da inteligência: o futuro do pensamento na era da informática. Rio de Janeiro: Editora 34, 6a reimpressão. 1990/1998. 
Oliveira, R.M. "Tecnologia e subjetivação: a questão da agência"

Rosana Medeiros de Oliveira é doutoranda no

departamento de História da Universidade de

Brasília; linha de pesquisa "Estudos feministas e de gênero".O endereço eletrônico da autora é: rosanamedeiros@terra.com.br

\section{Rosana Medeiros de Oliveira}

Tecnologia e subjetivação:

a questão da agência.

Recebido: 13/10/2004

$1^{\text {a }}$ revisão: 23/03/2005

Aceite final: 26/04/2005 